\title{
Smear Layer and Debris Removal Following use of WaveOne and OneShape Single-File Systems: SEM Study
}

\author{
${ }^{1}$ Mustafa Murat Koçak, ${ }^{2}$ Sibel Koçak, ${ }^{3}$ Baran Can Saglam, ${ }^{4}$ Sevinç Aktemur Türker
}

\begin{abstract}
Introduction: The aim of study was to evaluate the cleaning efficacy of two single-file NiTi systems.
\end{abstract}

\begin{abstract}
Materials and methods: Twenty-four mandibular premolars were selected. Two longitudinal grooves were prepared on the buccal and lingual surfaces. The roots were divided into groups (Group 1-WaveOne, Group 2-OneShape). The irrigation was performed using $2 \mathrm{ml}$ of $5.25 \% \mathrm{NaOCl}$ solution, $2 \mathrm{ml}$ of $17 \%$ EDTA solution, and $2 \mathrm{ml}$ saline. The roots were split longitudinally for SEM investigation. Serial SEM photomicrographs were taken under magnification at levels apical, middle and coronal thirds. The absence/presence of smear layer, pulpal debris and inorganic debris and the surface profile were scored.
\end{abstract}

Results: No difference was found between two instruments in terms of presence of smear layer, pulpal debris, and inorganic debris $(p<0.05)$. The surface scores of canals prepared with WaveOne were significantly higher.

Keywords: Pulpal debris, Scanning electron microscopy, Smear layer.

How to cite this article: Koçak MM, Koçak S, Saglam BC, Türker SA. Smear Layer and Debris Removal Following use of WaveOne and OneShape Single-File Systems: SEM Study. Int J Experiment Dent Sci 2014;3(2):77-83.

Source of support: Nil

Conflict of interest: None

\section{INTRODUCTION}

Preparation of root canals using files is one of the most essential stages for the success of endodontic treatment. The aim of this preparation is to shape the entire root canal by removing existing or potential irritants before obturation. There are numerous instruments, including hand files, ultrasonic devices, and engine-driven nickel-titanium (NiTi) rotary files, for shaping the root canal. As both manual and mechanical shaping produce smear layer and debris, ${ }^{1,2}$ it

\footnotetext{
${ }^{1}$ Associate Professor, ${ }^{2-4}$ Assistant Professor

${ }^{1-4}$ Department of Endodontics, Faculty of Dentistry, Bülent Ecevit University, Turkey

Corresponding Author: Mustafa Murat Koçak, Associate Professor, Department of Endodontics, Faculty of Dentistry Bülent Ecevit University, Turkey, Phone: 0903722613404 e-mail:mmuratkocak@yahoo.com
}

is important to develop an instrumentation technique for endodontic treatment that produces a minimal amount of smear layer and debris in order to obtain the optimum sealing of the root canals. ${ }^{3}$

Recently, new rotary NiTi single-file systems with different configuration designs have been marketed as WaveOne and OneShape. Although, both systems consist of a single file, they have different alloy properties and working principles. The WaveOne file is made of a special NiTi-alloy called M-Wire that is created by thermal-treatment process. The benefits of M-Wire NiTi are increased flexibility of the instruments and improved resistance to cyclic fatigue. ${ }^{4}$ The file is used in a reciprocal motion that requires special automated devices. In contrast, the OneShape file is made of a conventional austenite 55- NiTi alloy and is used in a full clockwise rotating motion. ${ }^{5}$ Limited data are available concerning the shaping ability and cleaning efficiency of these recently introduced instruments.

The aim of this study was to evaluate the cleaning efficacy and morphology of root canal walls after preparation with two single-file NiTi systems. The amount and the morphology of the smear layer, the presence of pulpal and dentinal debris, and the morphology of inner dentin walls were parameters for the evaluation of shaping and cleaning efficacy.

\section{MATERIALS AND METHODS}

\section{Selection of Samples}

Twenty-four freshly extracted single-rooted mandibular premolars were selected. Single root canal morphology was confirmed by digital radiographs. After extraction, the teeth were cleaned to remove soft tissues and calculus and stored in a $0.1 \%$ thymol solution.

\section{Root Canal Preparation}

For standardization, the crowns of all teeth were removed at the level of the cementoenamel junction in order to obtain roots approximately $13 \mathrm{~mm}$ in length. Two longitudinal grooves were prepared on the buccal and lingual surfaces of each root with a diamond bur used with a high-speed, watercooled handpiece to facilitate vertical splitting with a chisel after root canal preparation. Teeth showing evidence that the groove had penetrated into the root canal or exhibiting 
an irregular cleavage were discarded and replaced with a new specimen. The working length (WL) of each canal was determined as $1 \mathrm{~mm}$ short of the length that a size $15 \mathrm{~K}$-file was visible at the major diameter of the apical foramen. The roots were randomly divided into two groups according to the single file used. The groups were as follows:

Group 1: A primary reciprocating WaveOne (Dentsply Maillefer, Ballaigues, Switzerland) size 25 file with a taper of 0.08 was used in a reciprocating, slow in-and-out pecking motion with a 6:1 contra-angle handpiece (Sirona, Bensheim, Germany) powered by a torque-limited electric motor (VDW Silver Reciproc motor; VDW GmbH, München, Germany) according to the manufacturer's instructions. The flutes of the instrument were cleaned after three pecks. No glide path was created prior to instrumentation with the WaveOne file.

Group 2: A size 25 OneShape file (Micro Mega, Besancon, France) with a taper of 0.06 in a rotating motion was used in a 16:1 gear reduction hand-piece powered by a torque-controlled electric motor (X-Smart Europe; Dentsply, Tokyo, Japan) at a consistent rotation of $400 \mathrm{rpm}$. The torque was adjusted to $4 \mathrm{Ncm}$ according to the manufacturer's instructions.

In both groups, individual instruments were discarded after use in each root canal and irrigation was performed using $2 \mathrm{ml}$ of $5.25 \% \mathrm{NaOCl}$ solution followed by $2 \mathrm{ml}$ of a 17\% EDTA solution and a final rinse with $2 \mathrm{ml}$ saline. The needle was inserted as deep as possible into the root canal without binding. At the completion of the root canal preparation, each canal was flushed for 1 minute with $2 \mathrm{ml}$ of $17 \%$ EDTA solution, which was then washed with $2 \mathrm{ml}$ of $5.25 \% \mathrm{NaOCl}$ solution followed by copious rinsing with $4 \mathrm{ml}$ saline to eliminate the residual effects of the irrigants. After the complete instrumentation and irrigation, the canals were dried with sterile paper points. The irrigation protocol used in the present study was previously described by Zmener et al. ${ }^{6}$ After preparation, the specimens were stored in $100 \%$ relative humidity at $37^{\circ} \mathrm{C}$ until further use.

All of the instrumentation procedures were completed by one operator, and the SEM evaluations were carried out by a second examiner who was blind with respect to all experimental groups.

\section{SEM Evaluation}

The roots were split longitudinally and prepared for SEM investigation. Each specimen was coded and mounted on an aluminum stub, coated with gold-palladium, and examined under a scanning electron microscope (SEM) (Quanta ${ }^{\mathrm{TM}}$ 450 FEG, FEI, Oregon, USA). Serial scanning electron photomicrographs were made at $500 \times, 1000 \times$ and $2000 \times$ magnification covering the total circumference of the canal walls at levels coronal thirds of the root canal prepared by WaveOne (Figs 1A to C), middle thirds of the root canal prepared by WaveOne (Figs 2A to C), apical thirds of the root canal prepared by WaveOne (Figs $3 \mathrm{~A}$ to $\mathrm{C}$ ) and coronal thirds of the root canal prepared by OneShape (Figs 4A to C), middle thirds of the root canal prepared by OneShape (Figs 5A to C), and apical thirds of the root canal prepared by OneShape (Figs 6A to C).

\section{Scoring System}

The absence or presence of a smear layer, pulpal debris, and inorganic debris was scored using a predefined scale and selected SEM pictures. ${ }^{7,8}$ To assess the dentin surface profile the presence of grooves, pits and predentin areas was evaluated (Table 1).

Statistical analysis was performed with SPSS 18.0 software (SPSS Inc., Chicago, IL, USA). Distribution of data was determined by Shapiro-Wilks test. Continuous variables were expressed as mean $\pm \mathrm{SD}$. Variables were compared with the Mann-Whitney U test for the two groups. KruskalWallis test was used to determine the differences between the three groups. Bonferroni adjusted Mann-Whitney U test was used for post-hoc test after the Kruskal-Wallis test. p-value of less than 0.05 was considered statistically significant for all tests.

\section{RESULTS}

No instrument fracture or loss of working length occured during the preparation of the root canals. No difference was found between the two instruments in terms of the presence of smear layer $(\mathrm{p}=0.375)$, pulpal debris $(\mathrm{p}=$ $0.835)$, or inorganic debris $(\mathrm{p}=0.800)$. However, when surface profiles were compared, a significant difference was observed. The surface scores of canals prepared with WaveOne were significantly higher than the canals prepared with OneShape $(p=0.017)$. The grooves were frequently observed, especially in specimens prepared with WaveOne (group 1). The mean scores and standard deviations (SD) of the smear, pulpal debris, inorganic debris, and surface profile are shown in Table 2.

WaveOne demonstrated similar results in terms of the smear layer for apical, middle, and coronal regions ( $p=$ $0.096)$. The scores of pulpal debris $(\mathrm{p}=0.017)$, inorganic debris $(\mathrm{p}=0.012)$, and surface profile $(\mathrm{p}=0.001)$ demonstrated significant differences between apical and coronal regions. However, no difference was found between the middle and other two surfaces (apical and coronal).

For the root canals prepared with OneShape, the scores of the smear layer $(p=0.016)$, inorganic debris $(p=0.012)$, 

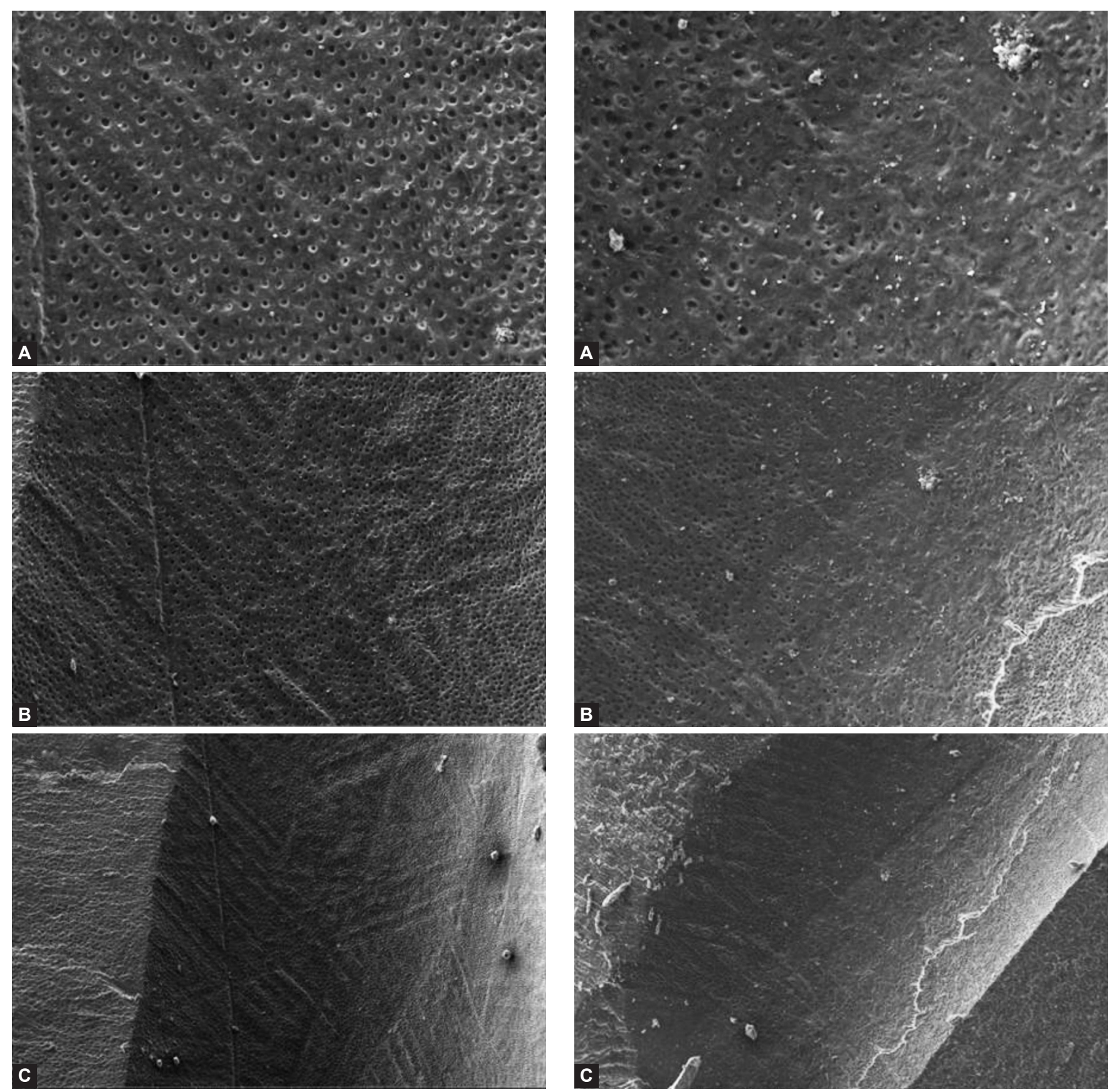

Figs 1A to C: Coronal thirds prepared by WaveOne file

Figs 2A to C: Middle thirds prepared by WaveOne file

Table 1: Scale of values assigned to the parameters evaluated

\begin{tabular}{|c|c|c|c|c|}
\hline & 1 & 2 & 3 & 4 \\
\hline Smear layer & $\begin{array}{l}\text { Absent, more than } 75 \% \\
\text { of tubules exposed and } \\
\text { free from smear layer } \\
\text { Tubules completely } \\
\text { opened }\end{array}$ & $\begin{array}{l}\text { Present in limited areas, } \\
\text { less than } 75 \% \text { of tubules } \\
\text { uncovered } \\
\text { Tubules partially opened }\end{array}$ & $\begin{array}{l}\text { Present, tubules visible in } \\
\text { limited areas and partially } \\
\text { closed } \\
\text { Less than } 50 \% \text { of } \\
\text { dentinal tubules visible }\end{array}$ & $\begin{array}{l}\text { Homogeneous smear } \\
\text { layer present above all } \\
\text { dentin } \\
\text { Dentinal tubules not } \\
\text { visible }\end{array}$ \\
\hline Pulpal debris & Absent & $\begin{array}{l}\text { Minimal presence of } \\
\text { pulpal-fibrous debris }\end{array}$ & $\begin{array}{l}\text { Partial presence of } \\
\text { pulpal-fibrous debris }\end{array}$ & $\begin{array}{l}\text { Presence of an organized } \\
\text { collagenous matrix }\end{array}$ \\
\hline Inorganic debris & Absent & Minimal presence & Often present & $\begin{array}{l}\text { Present everywhere and } \\
\text { covering dentin surface }\end{array}$ \\
\hline Surface profile & Absence of irregularities & $\begin{array}{l}\text { Isolated irregularities and } \\
\text { grooves }\end{array}$ & $\begin{array}{l}\text { Partially irregular with } \\
\text { limited noninstrumented } \\
\text { areas }\end{array}$ & $\begin{array}{l}\text { Irregular with grooves, } \\
\text { areas of uninstrumented } \\
\text { dentin }\end{array}$ \\
\hline
\end{tabular}



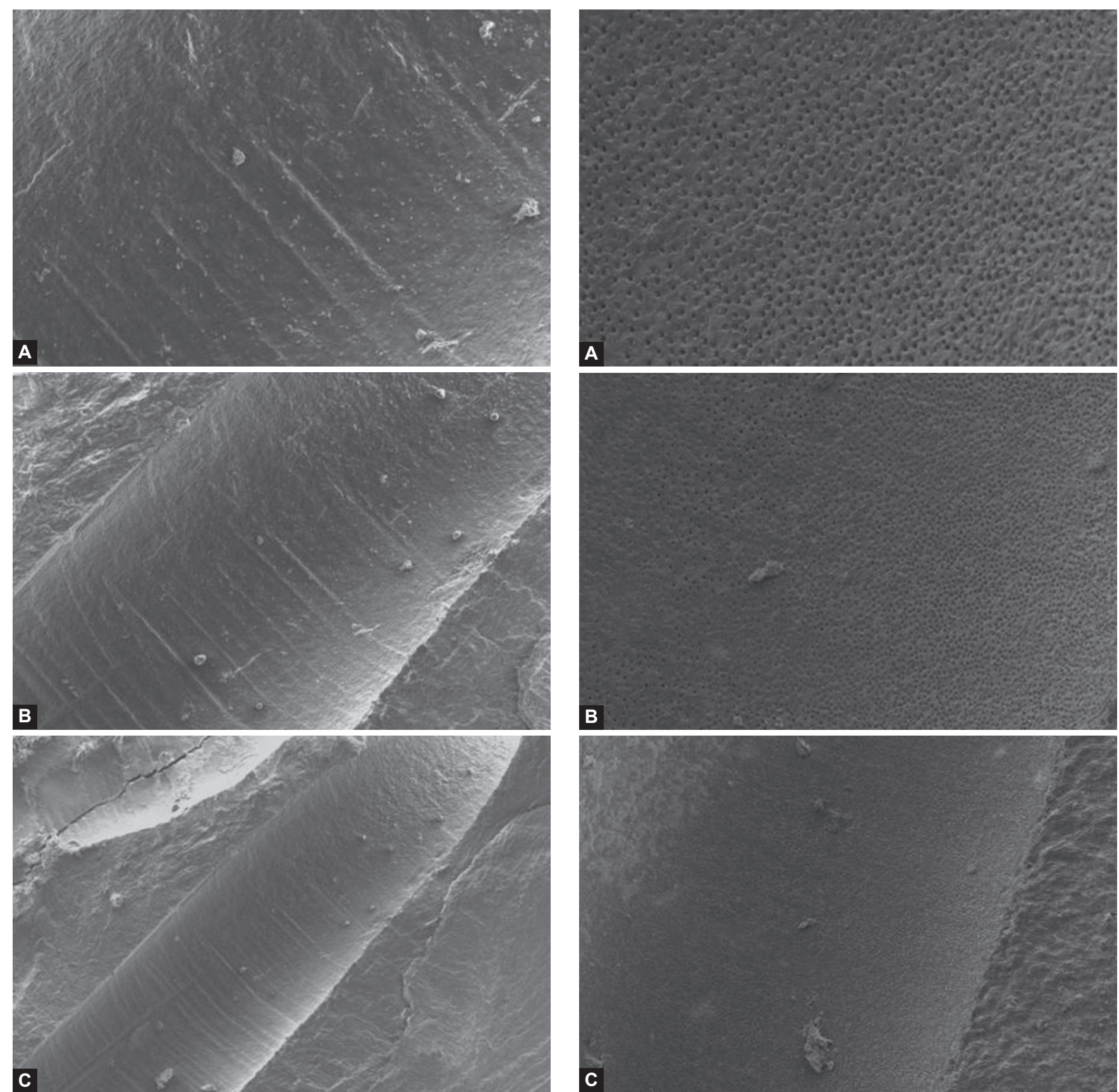

Figs 3A to C: Apical thirds prepared by WaveOne file

Table 2: The mean scores and SD of the parameters evaluated

\begin{tabular}{llll}
\hline Parameter & Groups & $n$ & Mean $(S D)$ \\
\hline Smear layer & WaveOne & 36 & $1.94( \pm 0.715)$ \\
& OneShape & 36 & $2.08( \pm 0.770)$ \\
Pulpal debris & WaveOne & 36 & $1.72( \pm 0.566)$ \\
Inorganic debris & OneShape & 36 & $1.72( \pm 0.659)$ \\
& WaveOne & 36 & $2.19( \pm 0.624)$ \\
Surface profile & OneShape & 36 & $2.11( \pm 0.622)$ \\
& WaveOne & 36 & $2.31( \pm 0.624)$ \\
& OneShape & 36 & $1.97( \pm 0.506)$ \\
\hline
\end{tabular}

Different letters demonstrate significant differences

and surface profile $(\mathrm{p}=0.049)$ were significantly different between apical and coronal regions. No difference was found between the middle third and the other two surfaces

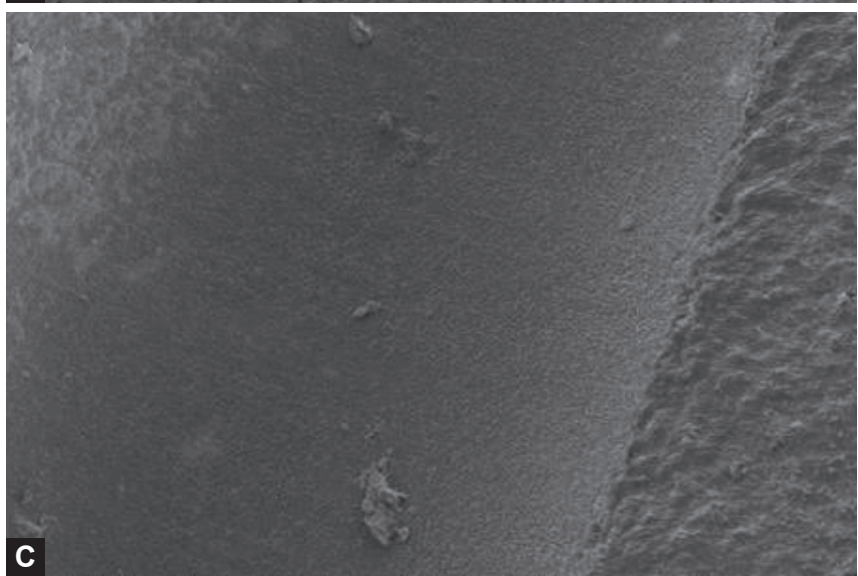

Figs 4A to C: Coronal thirds prepared by OneShape file

(apical and coronal). On the other hand, the scores of pulpal debris were significantly higher in apical region compared to coronal and middle $(\mathrm{p}=0.017)$ (Figs 1A to C).

\section{DISCUSSION}

The aim of present study was to compare the cleaning efficacy of two single-file systems, WaveOne and OneShape, with serial scanning electron photomicrographs under various magnifications. SEM analysis appears to be an adequate method to investigate the influence of endodontic instruments on the morphology of dentin surfaces, and it has been well-described. ${ }^{3}$ SEM offers high-resolution images and allows the observation of areas covered by debris 

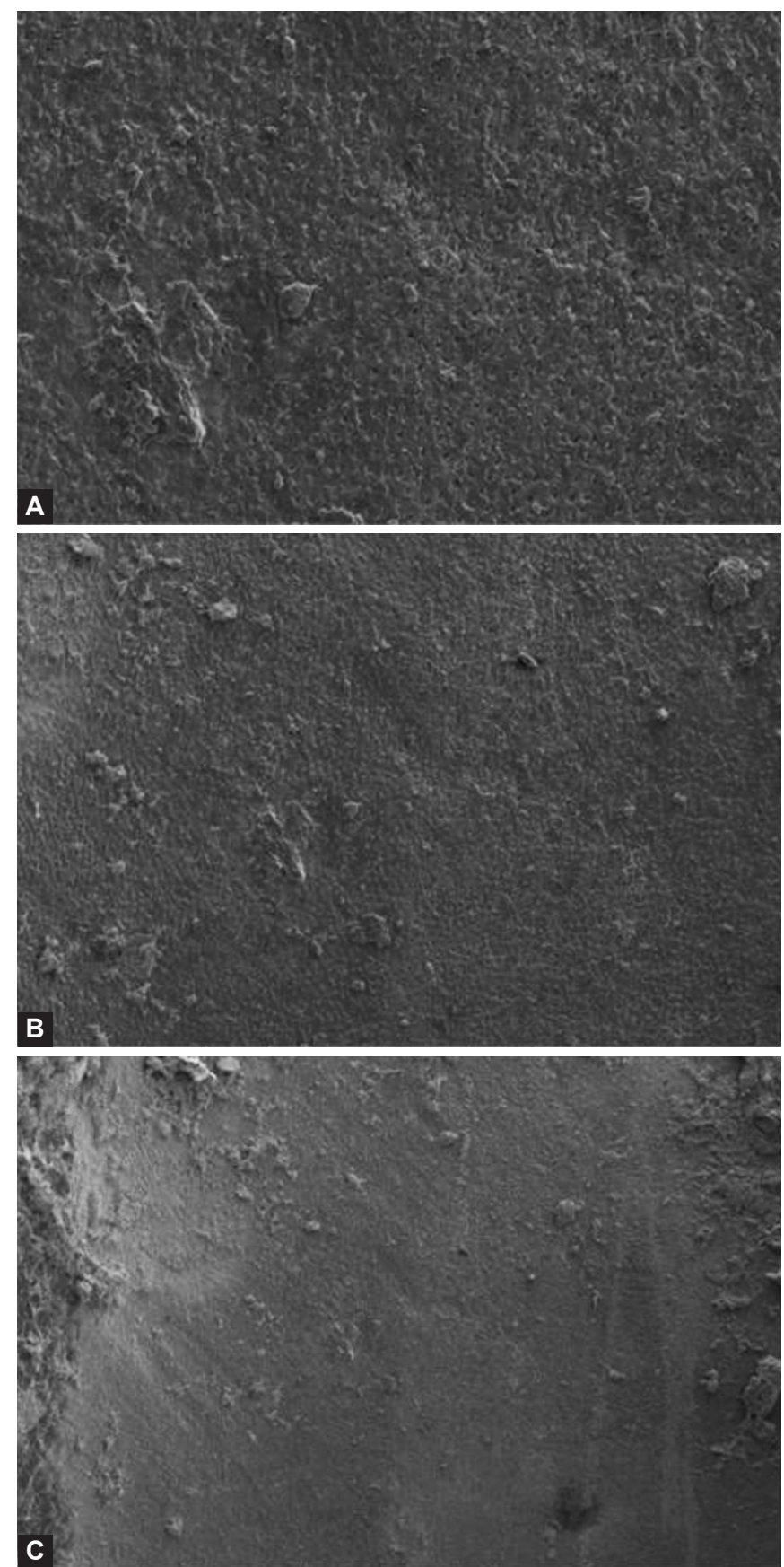

Figs 5A to C: Middle thirds prepared by OneShape file

and/or smear layer as well as the identification of patent dentinal tubules. ${ }^{8}$ Magnifications varying from $200 \times$ to $15000 \times$ were used to evaluate the cleanliness of the root canal surfaces. ${ }^{7-12}$ Ahlquist et al employed a magnification of $200 \times$ since it offered a wider view and a detailed image of the surface and the micrographs were taken at a $1500 \times$ magnification. ${ }^{3}$ However, there is no current consensus on the standardization of measurements of debris and the smear layer. ${ }^{3}$ In the present study, $500 \times$ magnification was employed and provided a good view for evaluating the detailed image of the root surface and dentinal tubules. The micrographs at greater magnifications $(1000 \times, 2000 \times)$ were used to evaluate the specific areas of dentin. Evaluation at high
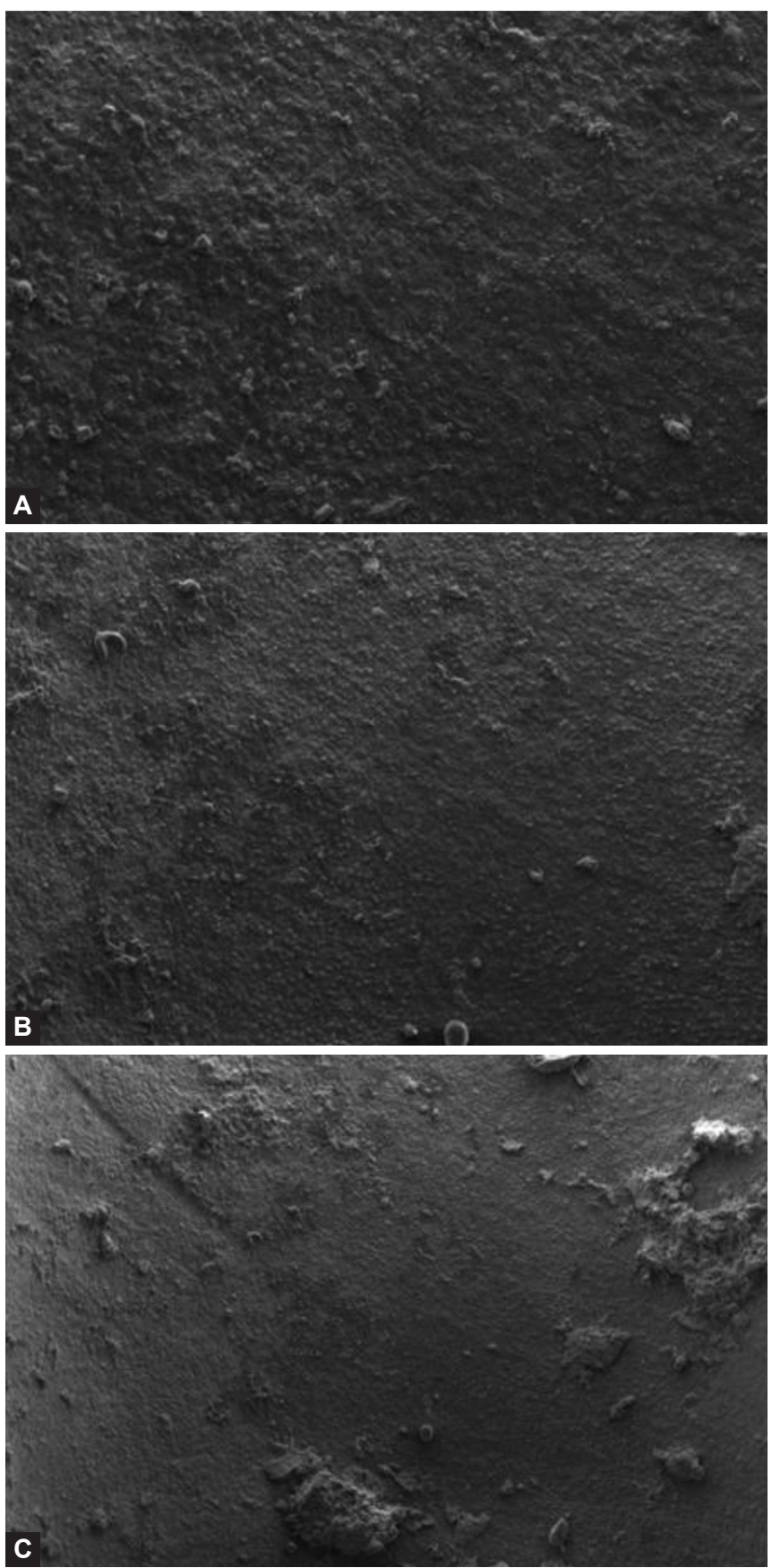

Figs 6 A to C: Apical thirds prepared by OneShape file

magnifications without supporting images at low magnifications may give limited and/or misleading information about the surface since these images reflect surfaces that are too small. Therefore, in the present study, the scoring of samples was carried out after a careful and combined evaluation of three selected magnifications.

Previous studies have reported that neither instruments nor techniques achieve complete cleanliness of canal walls. ${ }^{3,6}$ Our results supported this finding and demonstrated that none of the instruments and/or working principles tested was able to completely create smear and/or pulpal/inorganic debris-free root canal surfaces. This study also compared the efficacy of the working principles of the files selected 
-reciprocating motion and full clockwise rotation motion- in terms of root canal wall cleanliness. The reciprocation working motion consists of a counterclockwise (cutting direction) and a clockwise motion (release of the instrument), while the angle of the counterclockwise cutting direction is greater than the angle of the reverse direction. ${ }^{10}$ Only the surface profile demonstrated significant differences between the two instrumentation techniques. The grooves were significantly more frequent in the canals prepared with a reciprocating motion than in the canals prepared with a continuous rotation motion. This result may be due to the clockwise and counterclockwise motion property of reciprocation. OneShape instruments have a variable pitch length along the working part. The superiority on the surface profile may be due to the design of the instrument. On the other hand, preparation with reciprocating or full rotation resulted in similar efficacy in terms of the presence of smear layer and pulpal-inorganic debris.

Both files demonstrated significant levels of cleanliness and the removal of the smear layer at the coronal third compared to the apical, in accordance with the findings of previous studies. ${ }^{7,9,11}$ Although the tested files have different tapers, 0.08 apical taper for WaveOne that reduces toward the coronal end and 0.06 for OneShape, both files were effective in cleaning the root canal surfaces at the coronal thirds. A recent study revealed that root canal preparation with different tapers did not affect canal cleanliness. ${ }^{12}$ Similarly, we concluded that 0.08 and 0.06 tapered files demonstrated similar efficiency in cleaning the root canal walls.

The size of the apical root canal enlargement is still controversial regarding the maximum cleaning efficiency in this crucial part of the root canal. ${ }^{10,13}$ A previous investigation indicated that the difference between the apical preparation diameter was not responsible for the final outcome of the shaped canals using different instruments. ${ }^{10}$ In addition, an analysis of the treatment variables demonstrated that apical preparation size displayed no impact on treatment outcomes. $^{14}$

In the present study, both instruments demonstrated high scores for the removal of pulpal and inorganic debris and a surface profile in the apical third compared to coronal thirds, with statistical differences. The high amount of debris in the apical thirds may be due to the tip diameter of instruments used. Both selected instruments have a tip diameter equivalent to a size 25. Although greater size of instruments (\#35-40) are used for the preparation of premolar teeth, the OneShape instrument is not available at size over 25. To achieve equitable results, size 25 was selected for WaveOne, despite size 40 being available in the market. The scores obtained from our study supported similar previous studies. Sabet and Lutfy ${ }^{9}$ and Yang et $\mathrm{al}^{15}$ compared various full-sequence NiTi instruments and reported that all systems produced clean and debris-free dentin surfaces in the coronal and the middle thirds, but they were unable to produce a canal surface free from debris and smear layer in the apical thirds. Our results showed that there were no additional advantages or disadvantages of single-file systems at the apical thirds, according to smear layer and debris removal, and both instruments failed to produce clean and debris-free surfaces in the apical third. However, a significant decrease in preparation time by usage of single-file systems may be an advantage in clinical practice. ${ }^{10}$

The recently introduced NiTi file WaveOne is claimed to be able to completely prepare and clean root canals with only one instrument. These files are used in a reciprocal motion that requires special automated devices. In the present study, by strictly following the manufacturer's recommandations, the completion of root canal treatment was achieved without any instrument fracture in WaveOne single-file system group. Moreover, WaveOne produced clean and debrisfree dentin surfaces in the coronal thirds, and to a lesser extent, in the middle thirds, but was unable to clean apical third efficiently. OneShape demonstrated similar results for all root canal surfaces. However, there is no need to have an additional specific motor during the preparation with OneShape file. These files can be attached to traditional endo handpiece placed or any other endodontic motor with continuous rotation. This difference may be suggested as an advantage in clinical practice.

Based on the results of this study, independent from the systems used, both instruments and preparation motions were unable to produce completely clean root canal surfaces. Further studies are necessary to evaluate the behavior of the newly introduced NiTi systems in complicated root canals.

Under the conditions of this study, both instruments produced less smear layer and debris-free canal surfaces in the coronal and middle thirds, but they were unable to produce a canal surface free from debris and a smear layer in the apical third.

Dentistry is varying with induction of modern science to practice dentistry. ${ }^{16}$

\section{REFERENCES}

1. Heard F, Walton RE. Scanning electron microscope study comparing four root canal preparation techniques in small curved canals. Int Endod J 1997;30(5):323-231.

2. Hülsmann M, Stryga F. Comparison of root canal preparation using different automated devices and hand instrumentation. J Endod 1993;19(3):141-145.

3. Ahlquist M, Henningsson O, Hultenby K, Ohlin J. The effectiveness of manual and rotary techniques in the cleaning of root canals: a scanning electron microscopy study. Int Endod J 2001;34(7):533-537. 
4. Shen Y, Cheung GS, Bian Z, Peng B. Comparison of defects in ProFile and ProTaper systems after clinical use. J Endod 2006; 32(1):61-65.

5. Bürklein S, Benten S, Schäfer E. Shaping ability of different single-file systems in severely curved root canals of extracted teeth. Int Endod J 2013;46(6):590-597.

6. Zmener O, Pameijer CH, Banegas G. Effectiveness in cleaning oval-shaped root canals using anatomic endodontic technology, ProFile and manual instrumentation: a scanning electron microscopic study. Int Endod J 2005;38(6):356-363.

7. Foschi F, Nucci C, Montebugnoli L, Marchionni S, Breschi L, Malagnino VA, et al. SEM evaluation of canal wall dentine following use of Mtwo and ProTaper NiTi rotary instruments. Int Endod J 2004;37(12):832-839.

8. Prati C, Foschi F, Nucci C, Montebugnoli L, Marchionni S. Appearance of the root canal walls after preparation with NiTi rotary instruments: a comparative SEM investigation. Clin Oral Invest 2004;8(2):102-110.

9. Sabet NE, Lutfy RA. Ultrastructural morphologic evaluation of root canal walls prepared by two rotary nickel-titanium systems: a comparative study. Oral Surg Oral Med Oral Pathol Oral Radiol Endod 2008;106(3):e59-e66.
10. Bürklein S, Hinschitza K, Dammaschke T, Schäfer E. Shaping ability and cleaning effectiveness of two single-file systems in severely curved root canals of extracted teeth: Reciproc and WaveOne versus Mtwo and ProTaper. Int Endod J 2012;45(5):449-461.

11. Schäfer E, Zapke K. A comparative scanning electron microscopic investigation of the efficacy of manual and automated instrumentation of root canals. J Endod 2000;26(11):660-664.

12. Arvaniti IS, Khabbaz MG. Influence of root canal taper on its cleanliness: a scanning electron microscopic study. J Endod 2011;37(6):871-874.

13. Falk KW, Sedgley CM. The influence of preparation size on the mechanical efficacy of root canal irrigation in vitro. J Endod 2005;31(10):742-745.

14. Ørstavik D, Qvist V, Stoltze K. A multivariate analysis of the outcome of endodontic treatment. Eur J Oral Sci 2004;112(3):224-230.

15. Yang G, Wu H, Zheng Y, Zhang H, Li H, Zhou X. Scanning electron microscopic evaluation of debris and smear layer remaining following use of ProTaper and Hero Shaper instruments in combination with $\mathrm{NaOCl}$ and EDTA irrigation. Oral Surg Oral Med Oral Pathol Oral Radiol Endod 2008;106(4): e63-e71.

16. Saini R. Ozone therapy in dentistry: A strategic review. J Nat Sc Biol Med 2011;2:151-153. 